NASA Contractor Report 4328

\title{
Aircraft Design for Mission Performance Using Nonlinear Multiobjective Optimization Methods
}

Augustine R. Dovi and Gregory A. Wrenn

CONTRACT NAS1-1900

OCTOBER 1990

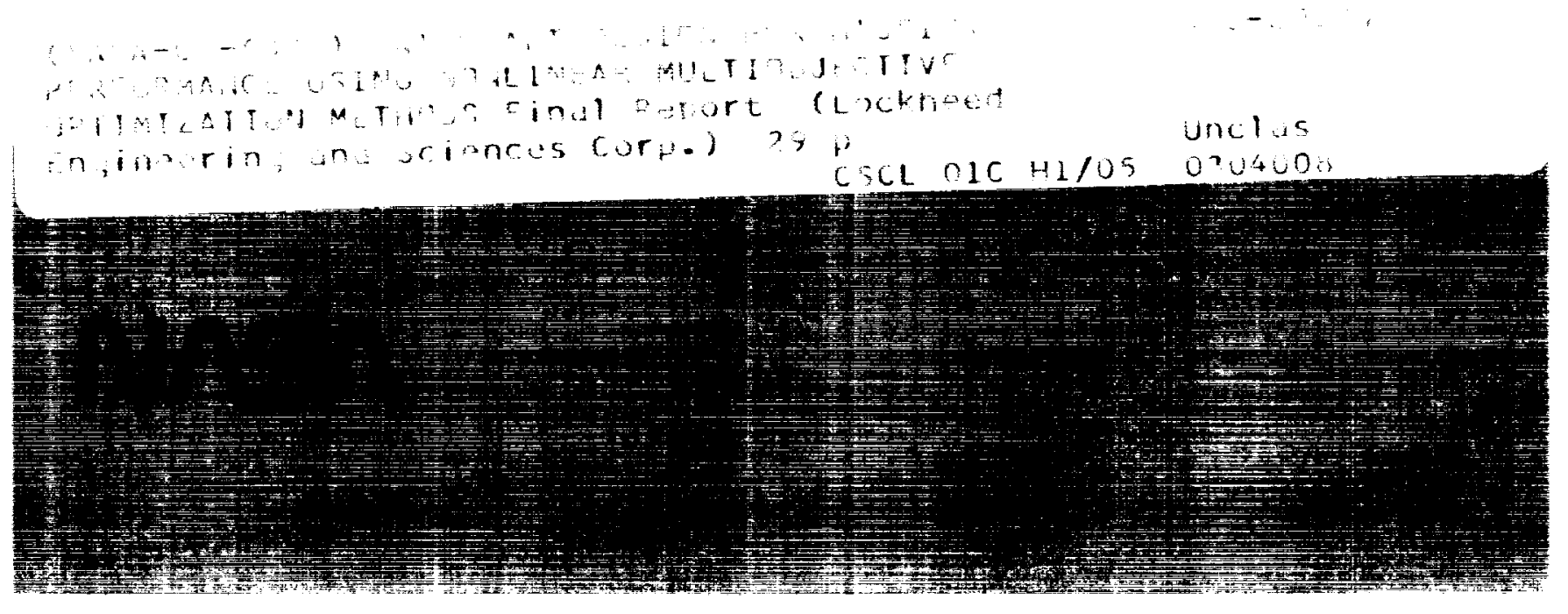




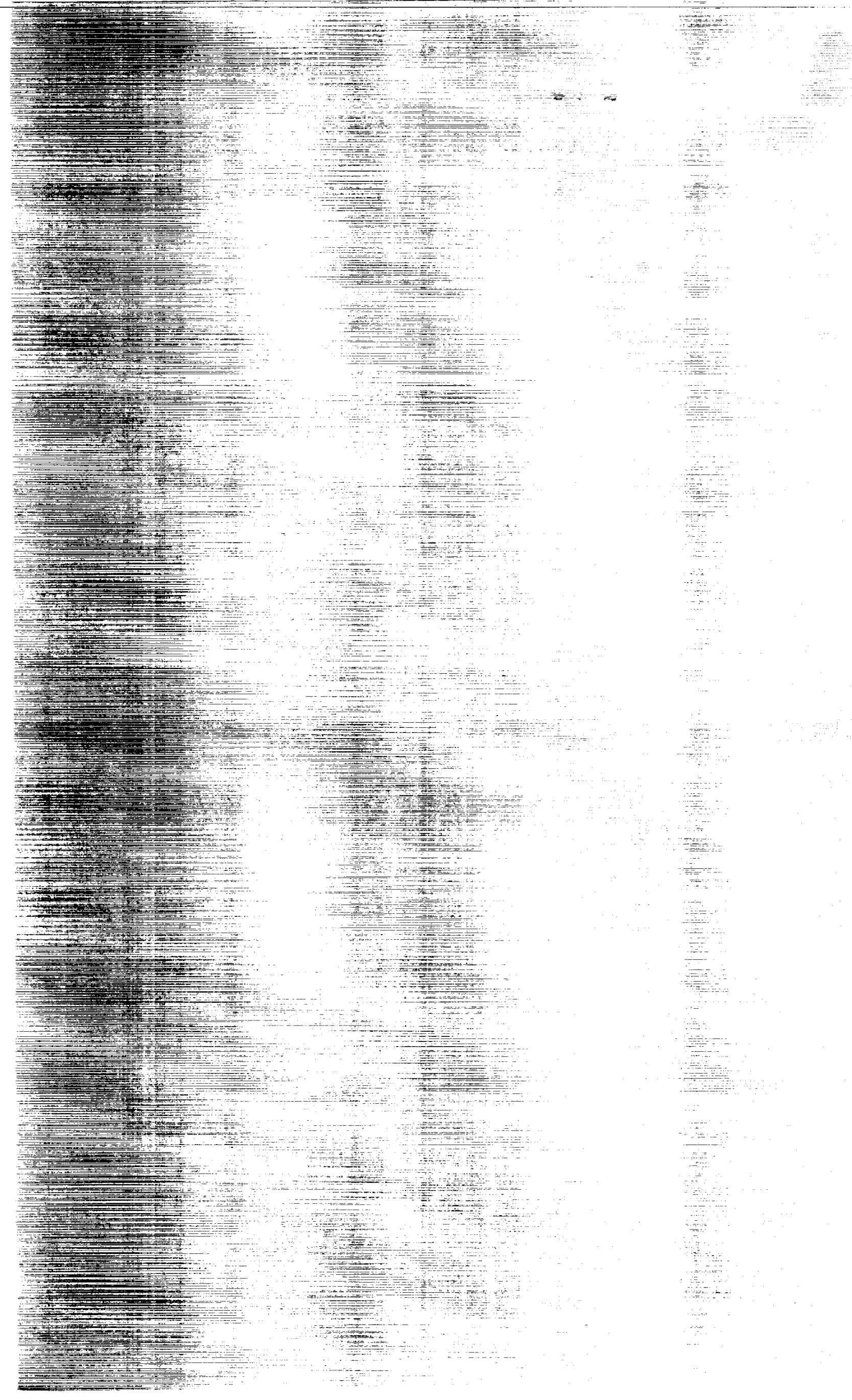


NASA Contractor Report 4328

\section{Aircraft Design for Mission Performance Using \\ Nonlinear Multiobjective Optimization Methods}

Augustine R. Dovi and Gregory A. Wrenn

Lockheed Engineering \& Sciences Company

Hampton, Virginia

Prepared for

Langley Research Center

under Contract NAS1 19000

\section{N/SA}

National Aeronautics and

Space Administration

Office of Management

Scientific and Technical

Information Division

1990 



\section{CONTENTS}

LIST OF TABLES iv

LIST OF FIGURES

SUMMARY

INTRODUCTION

GENERAL MULTIOBJECTIVE OPTIMIZATION

Formulation of the Mission/Performance Optimization Problem 3

Description of the Analysis System for Mission Performance 5

DESCRIPTION OF OBJECTIVE FUNCTION FORMULATION METHODS 6

Envelope Function Formulation (KSOPT) 6

Global Criterion Formulation $\quad 7$

Utility Function Formulation Using a Penalty Function Method 7

RESULTS AND DISCUSSION

Single Objective Function Optimization $\quad 8$

Parametric Results of the Design Space $\quad 10$

$\begin{array}{ll}\text { Multiobjective Optimization } & 10\end{array}$

Comparison of Two Objective With Single Objective Designs 10

Comparison of Three Objective With Single Objective Designs 11

Comparison with Overall Best Single Objective Designs 11

CONCLUSIONS 11

REFERENCES $\quad 13$ 


\section{LIST OF TABLES}

Table 1a: Multiobjective Cases $\quad 16$

Table 1b: Single Objective Cases $\quad 16$

Table 2: $\quad$ Single Objective Design Results 17

Table 3: $\quad$ Two Objective Design Results $\quad 18$

Table 4: $\quad$ Three Objective Design Results $\quad 19$

Table 5: $\quad$ Best Single Objective Results $\quad 20$ 


\section{LIST OF FIGURES}

$\begin{array}{lll}\text { Figure } 1 & \text { Objectives, Design Variables and Constraints } & 21\end{array}$

Figure 2 Mission Profile 21

Figure 3 FLOPS Primary Modules 22

Figure 4 Single Objective Optimization Change From Initial Conditions 22

Figure 5 Ramp Weight as a Function of Aspect Ratio and Thickness Ratio 22

Figure 6 Mission Fuel as a Function of Aspect Ratio and Thickness Ratio 22

Figure $7 \quad$ Mach (L/D) as a Function of Aspect Ratio and Thickness Ratio 22

Figure 8 Two Objective Optimization Compromise From Single 23

Figure 9 Three Objective Optimization Compromise From Single 23 Objective Cases

Figure 10 Two Objective Optimization Compromise From Best Single 23 Objective Cases

Figure 11 Three Objective Optimization Compromise From Best Single 23 Objective Cases 



\section{SUMMARY}

A new technique which converts a constrained optimization problem to an unconstrained one where conflicting figures of merit may be simultaneously considered has been combined with a complex mission analysis system. The method is compared with existing single and multiobjective optimization methods. A primary benefit from this new method for multiobjective optimization is the elimination of separate optimizations for each objective, which is required by some optimization methods. A typical wide body transport aircraft is used for the comparative studies.

\section{INTRODUCTION}

Aircraft conceptual design is the process of determining an aircraft configuration which satisfies a set of mission requirements. Engineers within several diverse disciplines including but not limited to mass properties, aerodynamics, propulsion, structures and economics perform iterative parametric evaluations until a design is developed. Convention limits each discipline to a subset of configuration parameters, subject to a subset of design constraints, and typically, each discipline has a different figure of merit.

Advanced design methods have been built into synthesis systems such that communication between disciplines is automated to decrease design time ${ }^{1,2}$. Each discipline may select its own set of design goals and constraints resulting in a set of thumbprint and/or carpet plots from which a best design may be selected. In addition, the conceptual design problem has been demonstrated to be very amenable to the use of formal mathematical programming methods, and these algorithms have been implemented to quickly identify feasible designs $3,4,5$. 
The purpose of this report is to investigate the use of multiobjective optimization methods for conceptual aircraft design where conflicting figures of merit are considered simultaneously. Three multiobjective methods $6,7,8$ have been combined with a complex mission analysis system ${ }^{5}$. Trade-offs of the methods are compared with single objective results. In addition parametric results of the design space are presented. The aircraft chosen for this investigation is a typical wide body transport.

\section{GENERAL MULTIOBJECTIVE OPTIMIZATION}

The constrained multiobjective optimization problem stated in conventional formulation is to

minimize $F_{k}(X), k=1$ to number of objectives

such that,

$g_{j}(X) \leq 0, \quad j=1$ to number of constraints

and

$\mathbf{x}_{\mathrm{i}} \leq \mathrm{x}_{\mathrm{i}} \leq \mathrm{x}_{\mathrm{i}}^{\mathrm{u}_{\mathrm{i}}} \quad \mathrm{i}=1$ to number of design variables

where, $X=\left\{x_{1}, x_{2}, x_{3}, \ldots x_{n}\right\}^{T} n=$ number of design variables

The fundamental problem is to formulate a definition of $F_{k}(X)$, the objective vector, when its components have different units of measure thereby reducing the problem to a single objective. Several techniques have been devised to approach this problem 7 . The methods selected for study in this report transform the vector of objectives into a scalar 
function of the design variables. The constrained minimum for this function has the property that one or more constraints will be active and that any deviation from it will cause at least one of the components of the objective function vector to depart from its minimum, the classic Pareto-minimal solution 9,10 . One should add that multiobjective optimization results are expected to vary depending on the method of choice since the conversion method to a single scalar objective is not unique.

\section{Formulation of the Mission/Performance Optimization Problem}

The purpose of the optimization is to rapidly identify a feasible design to perform specific mission requirements, where several conflicting objectives and constraints are considered. The aircraft type selected for this study is a typical wide body transport, figure 1 , in the $22680 \mathrm{~kg}$ weight class ${ }^{11}$. The aircraft has three high-bypass ratio turbofan engines, with 6915 newtons thrust each. The mission requirements are

$\begin{array}{llc}\text { design range } & = & 7413.0 \mathrm{~km} \\ \text { cruise Mach number } & = & 0.83 \\ \text { cruise altitude } & = & 11.9 \mathrm{~km} \\ \text { payload } & = & 42185.0 \mathrm{~kg} \\ \text { number of passengers and crew } & = & 256\end{array}$

The primary and reserve mission profiles are shown in figure 2 .

The design variables considered, figure 1 , are aspect ratio $(A \mathrm{R})$, area $\left(\mathrm{S}_{\mathrm{W}}\right)$, quarter chord sweep $(\Lambda)$ and thickness to chord ratio $(t / c)$ of the wing, where the initial values chosen for all cases are 


$$
\mathrm{X}_{\mathrm{o}}=\left\{\begin{array}{c}
A \mathrm{R} \\
\mathrm{S}_{\mathrm{w}} \\
\Lambda \\
\mathrm{v} \mathrm{c}
\end{array}\right\}=\left\{\begin{array}{c}
11.0 \\
361.0 \mathrm{~m}^{2} \\
35.0 \mathrm{deg} \\
0.11
\end{array}\right\}
$$

The objectives to be minimized or maximized for this investigation include

$$
\begin{array}{ll}
F_{1}(X)= & \text { ramp weight (minimize) } \\
F_{2}(X)= & \text { mission fuel (minimize) } \\
F_{3}(X)= & \text { lift to drag ratio at constant cruise Mach number (maximize) } \\
F_{4}(X)= & \text { range with fixed ramp weight (maximize) }
\end{array}
$$

The functions to be maximized were formulated as negative values so that they could be used with a minimization algorithm. These objectives are first optimized for feasible single objective designs. The objectives are then considered simultaneously for multiobjective designs. Tables $1 \mathrm{a}$ and $1 \mathrm{~b}$ list fourteen cases, six multiobjective and eight single objective, along with the unconstrained objective function formulation used for each.

Each of the three formulations use the Davidon-Fletcher-Powell variable metric optimization method to compute the search direction for finding a local unconstrained minimum of a function of many variables ${ }^{12}$.

The inequality behavioral constraints used in each case are

$$
\begin{aligned}
& \mathrm{g}_{1}(\mathrm{X})=\text { lower limit on range, }(1853.2 \mathrm{~km}) \\
& \mathrm{g}_{2}(\mathrm{X})=\text { upper limit on approach speed, }(280.0 \mathrm{~km} / \mathrm{hr}) \\
& \mathrm{g}_{3}(\mathrm{X})=\text { upper limit on takeoff field length, }(2700.0 \mathrm{~m})
\end{aligned}
$$


$\mathrm{g}_{4}(\mathrm{X})=$ upper limit on landing field length, $(2700.0 \mathrm{~m})$

$\mathrm{g}_{5}(\mathrm{X})=$ lower limit on missed approach climb gradient thrust, (3458.0 newtons)

$\mathrm{g}_{6}(\mathrm{X})=$ lower limit on second segment climb gradient thrust, (3458.0 newtons)

$\mathrm{g}_{7}(\mathrm{X})=$ upper limit on mission fuel capacity (fuel capacity of wing plus fuselage)

where the constraint functions $\mathrm{g}_{\mathrm{j}}$ are written in terms of computable functions stated as demand $(X)$ and capacity. These functions provide the measure of what a design can sustain verses what it is asked to carry

$$
\mathrm{g}_{\mathrm{j}}(\mathrm{X})=\operatorname{demand}(\mathrm{X}) / \text { capacity }-1
$$

In addition, side constraints were imposed on wing sweep and wing area in the form of upper and lower bounds.

\section{Description of the Analysis System for Mission Performance}

The Flight Optimization System (FLOPS) is an aircraft configuration optimization system developed for use in conceptual design of new transport and fighter aircraft and the assessment of advanced technology5. The system is a computer program consisting of four primary modules shown in figure 3: weights, aerodynamics, mission performance, and takeoff and landing. The weights module uses statistical data from existing aircraft which were curve fit to form empirical wing weight equations using an optimization program. The transport data base includes aircraft from the small business jet to the jumbo jet class. Aerodynamic drag polars are generated using the empirical drag estimation technique ${ }^{13}$ in the aerodynamics module. The mission analysis module uses weight, aerodynamic data, and an engine deck to calculate performance. Based on energy considerations, an optimum climb profile is flown to the start of the cruise condition. The 
cruise segment may be flown for maximum range with ramp weight requirements specified; optimum Mach number for maximum endurance; minimum mission fuel requirements; and minimum ramp weight requirements. Takeoff and landing analyses include ground effects, while computing takeoff and landing field lengths to meet Federal Air Regulation (FAR) obstacle clearance requirements.

\section{DESCRIPTION OF OBJECTIVE FUNCTION FORMULATION METHODS}

\section{Envelope Function Formulation (KSOPT)}

This algorithm is a new technique for converting a constrained optimization

problem to an unconstrained one $\mathrm{e}^{6}$ and is easily adaptable for multiobjective optimization ${ }^{14}$. The conversion technique replaces the constraint and objective function boundaries in $\mathrm{n}$ dimensional space with a single surface. The method is based on a continually differentiable function 15 ,

$$
K S(X)=\frac{1}{\rho} \log _{e} \sum_{k=1}^{K} e^{f_{k}(X)}
$$

where $f_{k}(X)$ is a set of $K$ objective and constraint functions and $\rho$ controls the distance of the KS function surface from the maximum value of this set of functions evaluated at $\mathrm{X}$. Typical values of $\rho$ range from 5 to 200 . The KS function defines an envelope surface in $\mathrm{n}$-dimensional space representing the influence of all constraints and objectives of the mission analysis problem. The initial design may begin from a feasible or infeasible region. 


\section{Global Criterion Formulation}

The optimum design is found by minimizing the normalized sum of the squares of the relative difference of the objective functions. Single objective solutions are first obtained and are referred to as fixed target objectives. Computed values then attempt to match the fixed target objectives. Written in the generalized form

$$
F^{*}(X)=\sum_{k=1}^{K}\left[\frac{F_{k}^{T}(X)-F_{k}(X)}{F_{k}^{T}(X)}\right]^{2}
$$

where $F_{k}^{T}$ is the target value of the $k_{t h}$ objective and $F_{k}$ is the computed value. $F^{*}$ is the Global Criterion performance function ${ }^{7}$. The performance function $\mathrm{F}^{*}$ was then minimized using the KSOPT formulation described earlier.

\section{Utility Function Formulation Using a Penalty Function Method}

The optimum design is found by minimizing a utility function stated as

$$
F^{*}(X)=\sum_{k=1}^{K} w_{k} F_{k}(X)
$$

where $w_{k}$ is a designers choice weighting factor for the $k_{t h}$ objective function, $F_{k}$, to be minimized. This composite objective function is included in a quadratic extended interior penalty function ${ }^{16}$. This function is stated in generalized form as

$$
\widetilde{F}\left(X, r_{p}\right)=F^{*}(X)-r_{p} \sum_{j=1}^{m} G_{j}(X)
$$


and

$$
G_{j}(X)=\left\{\begin{array}{c}
\frac{1}{g_{j}(X)} \\
\frac{2 \varepsilon-g_{j}(X)}{\varepsilon^{2}}
\end{array}\right\} \begin{aligned}
& \text { for } g_{j}(X) \geq \varepsilon \\
& \text { for } g_{j}(X)<\varepsilon
\end{aligned}
$$

where the $r_{p} \sum_{j=1}^{m} G_{j}(X)$ term penalizes $\widetilde{F}\left(X, r_{p}\right)$, the performance function in proportion to the amount by which the constraints are violated and $\varepsilon$ is a designers choice transition parameter. The value of the penalty multiplier, $r_{p}$, is initially estimated based on the type of problem to be solved and is varied during the optimization process. The penalty multiplier, $\mathrm{r}_{\mathrm{p}}$, is made successively smaller to arrive at a constrained minimum.

\section{RESULTS AND DISCUSSION}

\section{Single Objective Function Optimization}

Single objective results for two of the methods are presented, the envelope function KSOPT and the classic penalty function PF methods. Single objective cases were run to establish a base line for comparison of multiobjective performance. In addition, target objectives are obtained for the Global Criterion Method. Final optimization values are presented in table 2 for both methods. Both techniques converged to very similar designs for all cases listed in table $1 \mathrm{~b}$. Greatest modifications from the initial design are seen in lift to drag ratio (L/D), cases 9 and 13 and range, cases 10 and 14 .

Lift to drag was modified by increasing the aspect ratio and wing area thus minimizing the wing loading (W/S). Thrust requirements (T/W) increased due to the larger ramp weight. In addition, the wing was made thinner and unswept. The KSOPT method 
converged to a $23 \%$ higher L/D verses the PF method. This is typically due to the way constraint boundaries are followed.

Range improvements, cases 10 and 14 , were accomplished by unsweeping the wing to the lower limit allowed and wing volume was adjusted to carry the maximum fuel load with reserves at the penalty of increased ramp weight. In addition, the optimizers reduced wing thickness, area and aspect ratio from initial values. Wing loading was kept at a minimum. KSOPT again produced a slightly better design compared with the PF method.

To minimize mission fuel requirements, cases 8 and 12, the aspect ratio was increased, and the wing area and was decreased. In addition, the wing was unswept and made thinner. This design improved aerodynamic performance by over $20 \%$ from the initial value while ramp weight increased slightly. The PF method converged to a slightly better design for this case.

Ramp weight, cases 7 and 11, was decreased by unsweeping the wing to the lower limit of 22.0 degrees. Aspect ratio is essentially unchanged from the initial condition design point. The wing thickness was decreased, along with a decrease in area. Aerodynamic performance was not penalized significantly from the initial design value. KSOPT produced a slightly lower ramp weight.

The chart in figure 4 compares the final design objective's percent change from the initial design point. 


\section{Parametric Results Of The Design Space}

Point designs, obtained parametrically, for minimum ramp weight, minimum mission fuel and maximum Mach (L/D) are shown in figures 5 through 7. Wing aspect ratio and thickness to chord ratio were varied, while other design variables were set to optimum values given in table 2, Case 8, Case 7 and Case 9, respectively. The design space is shown with the most critical constraints or criteria governing the design. To arrive at the optimum point designs shown by traditional parametric trade studies over 256 evaluations would have been required.

\section{Multiobjective Optimization}

Multiobjective optimization considers all conflicting design objectives and constraints simultaneously to meet mission specifications. Three methods are compared, the envelope function KSOPT, the Penalty Function (PF) method and Global Criterion (GC) method. Feasible designs were obtained for two objectives, table 3, and three objectives, table 4 , satisfying all constraints.

\section{Comparison Of Two Objective With Single Objective Design}

Figure 8 shows the percent deviation or compromise from each method's single objective design. KSOPT treated ramp weight and mission fuel equally where the PF and GC methods favored ramp weight, preferring to pay a larger penalty for mission fuel. This behavior is expected with the PF and GC methods since the ramp weight is larger in magnitude giving this objective greater influence. This effect could have been eliminated by judicious normalization or weighting. 


\section{Comparison Of Three Objective With Single Objective Design}

Figure 9 shows the percent deviation or compromise from each methods single objective design. KSOPT traded aerodynamic efficiency $(\mathrm{L} / \mathrm{D})$ and ramp weight to keep fuel requirements down. The $\mathrm{PF}$ method weighted $\mathrm{L} / \mathrm{D}$ to a greater extent since the weighting coefficient $w_{\mathbf{k}}$ was 10,000 , with small penalties in ramp weight and mission fuel. The GC penalty behavior is similar to the two objective results in that the ramp weight was weighted more over mission fuel and aerodynamic efficiency. The overall compromise is lowest for the PF method.

\section{Comparison With Overall Best Single Objective Designs}

The best single objective design results are listed in table 5 along with objectives and methods. Since L/D was not part of the objective function set, figure 10 , two objective compromised results behaved very similar to figure 8 . Three objectives, figure 11 , caused the design space to be more constrained. KSOPT again traded ramp weight and L/D to keep mission fuel requirements down. The PF method traded in a similar way but compromised L/D to a greater extent. The GC method gave more priority to ramp weight because of its magnitude. The overall compromise of KSOPT and PF were about the same at 26.3 and 24.4 percent respectively and the GC method 40.4 percent.

\section{CONCLUSIONS}

A typical wide body subsonic transport aircraft configuration was used to investigate the use of three multiobjective optimization methods, 1) an envelope of constraints and objectives, KSOPT, 2) a Penalty Function and 3) the Global Criterion. The methods were coupled with a complex mission performance analysis system. The 
optimizer used with all three methods is the Davison-Fletcher-Powell variable metric method for unconstrained optimization. Multiobjective compromised solutions were obtained for two and three objective functions. Feasible designs for each objective were also obtained using single objective optimization as well. The initial value design variable vector $\mathrm{X}_{0}$ and the constraints $\mathrm{g}_{1}$ through $\mathrm{g}_{7}$ were the same for all cases in this comparative study.

The KSOPT method was able to follow constraint boundaries closely and considered the influence of all constraints and objectives in a single continuously differentiable envelope function. KSOPT defines the optimum such that the function component with the greatest relative slope dominates the solution. The PF method also produced feasible designs similar to the KSOPT final designs for single objective optimization. This method, however, weights the individual objective functions in the multiobjective cases.

The GC method is usually applied to multiobjective problems but may be used in the single objective problem if a target objective is supplied. This would be equivalent to imposing an upper or lower bound on the performance function. The GC method has a disadvantage in resource requirements, requiring separate single objective optimizations to provide target objectives.

Computational effort has been measured in functional evaluations, shown in the tables of results. They are defined as the number of calls to the analysis procedures from the optimization procedures. Function evaluations are very similar for single objective cases except for mission fuel using KSOPT. This deviation is due to the methods implementation, convergence criteria and the way constraint boundaries are followed. The multiobjective table shows the GC method with the least functional evaluations, however 
single objective function evaluations must be included with these values thereby making it the most costly in terms of number of analyses.

All of the methods produced feasible solutions within the design space. Attributes of the methods, such as ease of use, data requirements and programming should also be considered when evaluating their performance along with computational efficiency. Many cases have been compared, too numerous to report herein, where initial design variables were changed up to 40 percent above and below the initial values given in this report. KSOPT continued to perform in a robust manner compared to the penalty function method. Producing similar final designs within 1 percent of the mean. Based on the results of this study and the above considerations, KSOPT is thus concluded to be a viable general method for multiobjective optimization. Finally, one should add that multiobjective optimization results are expected to vary depending on the method of choice.

\section{REFERENCES}

1. Radovcich, N. A., "Some Experiences in Aircraft Aeroelastic Design Using Preliminary Aeroelastic Design of Structures [PADS]", Part 1, CP-2327, April 1, 1984, pp. $455-503$.

2. Ladner, F. K., Roch, A. J., “A Summary of the Design Synthesis Process; SAWE paper No. 907 presented at the 31st Annual Conference of the Society of Aeronautical Weight Engineers; Atlanta, Georgia, 22-25 May 1972.

3. Piggott, B. A. M.; and Taylor, B. E., “Application of Numerical Optimisation Techniques to the Preliminary Design of a Transport Aircraft", Technical Report 71074, (British) R. A. E., April 1971. 
4. Sliwa, Steven M. and Arbuckle, P. Douglas, "OPDOT: A Computer Program for the Optimum Preliminary Design of a Transport Airplane", NASA TM-81857, 1980.

5. McCullers, L. A., "FLOPS - Flight Optimization System", Recent Experiences in Multidisciplinary Analysis and Optimization, Part 1, CP-2327, April 1984, pp. 395-412.

6. Wrenn, Gregory, A., "An Indirect Method for Numerical Optimization Using the Kreisselmeier-Steinhauser Function”, NASA CR-4220, March 1989.

7. Rao, S. S., "Multiobjective Optimization in Structural Design with Uncertain Parameters and Stochastic Processes". AIAA Journal, Vol. 22, No. 11, November 1984, pp. $1670-1678$.

8. Fox, Richard L., "Optimization Methods for Engineering Design". AddisonWesley Publishing Company, Inc., Menlo Part, CA, 1971, pp. 124-149.

9. Zadeh, L. H., "Optimality and Non-Scalar-valued Performance Criteria”, IEEE Transactions on Automatic Control, Vol. AC-8, No. 1, 1963.

10. Pareto, V., “Cours d'Economie Politiques Rouge, Lausanne, Switzerland, 1896.

11. Loftin, Laurence K., Jr., "Quest for Performance the Evolution of Modern Aircraft". NASA SP-468, 1985, pp. 437-452. 
12. Davidon, W. C., "Variable Metric Method for Minimization", Argonne National Laboratory, ANL-5990 Rev., University of Chicago, 1959.

13. Feagin, R. C. and Morrison, W. D., Jr., "Delta Method An Empirical Drag Buildup Technique”, NASA CR-151971, December 1978.

14. Sobieski-Sobieszczanski Jaroslaw; Dovi, Augustine R., and Wrenn, Gregory, A., “A New Algorithm for General Multiobjective Optimization”. NASA TM-100536, March 1988.

15. Kreisselmeier, G., Steinhauser, G., "Multilevel Approach to Optimum Structural Design", Journal of the Structural Division, ASCE, ST4, April, 1975, pp. 957974.

16. Cassis, Juan H., Schmit, Lucian, A., “On Implementation of the Extended Interior Penalty Function", International Journal for Numerical Methods in Engineering, Vol. 10, 3-23, 1976, pp. 3-23. 
Table 1a

Multiobjective Cases

\begin{tabular}{|c|c|}
\hline Case Number & \\
\hline 1 & KSOPT Multiobjectives \\
\hline 2 & $\begin{array}{c}\mathrm{F}_{1}(\mathrm{X}) \text { and } \mathrm{F}_{2}(\mathrm{X}) \\
\mathrm{F}_{1}(\mathrm{X}) \text { and } \mathrm{F}_{2}(\mathrm{X}) \text { and } \mathrm{F}_{3}(\mathrm{X})\end{array}$ \\
\hline & $\begin{array}{c}\text { Penalty Method } \\
\text { Weighted Composite } \\
\text { Multiobjectives }\end{array}$ \\
\hline 3 & $\mathrm{~F}_{1}(\mathrm{X})+\mathrm{F}_{2}(\mathrm{X})$ \\
4 & $\mathrm{~F}_{1}(\mathrm{X})+\mathrm{F}_{2}(\mathrm{X})+10,000.00 \mathrm{~F}_{3}(\mathrm{X})$ \\
\hline & $\begin{array}{c}\text { Global Criterion Method } \\
\text { Target Objectives }\end{array}$ \\
\hline 5 & $\mathrm{~F}_{1}^{\mathrm{T}}(\mathrm{X})=201629.0 \mathrm{~kg}$ and \\
& $\mathrm{F}_{2}^{\mathrm{T}}(\mathrm{X})=60954.0 \mathrm{~kg}$ \\
& $\mathrm{~F}_{1}^{\mathrm{T}}(\mathrm{X})=201629.0 \mathrm{~kg}$ and \\
& $\mathrm{F}_{2}^{\mathrm{T}}(\mathrm{X})=60954.0 \mathrm{~kg}$ and \\
& $\mathrm{F}_{3}^{\mathrm{T}}(\mathrm{X})=\mathrm{M}(28.1)$ \\
\hline
\end{tabular}

Table 1b

Single Objective Cases

\begin{tabular}{|c|c|}
\hline Case Number & \\
\hline & KSOPT Single objectives \\
\hline 7 & $F_{1}(X)$ \\
9 & $F_{2}(X)$ \\
10 & $F_{3}(X)$ \\
& $F_{4}(X)$ \\
\hline 11 & Penalty Method \\
12 & Single Objectives \\
13 & $F_{1}(X)$ \\
14 & $F_{2}(X)$ \\
\hline
\end{tabular}


Table 2

Single Objective Design Results

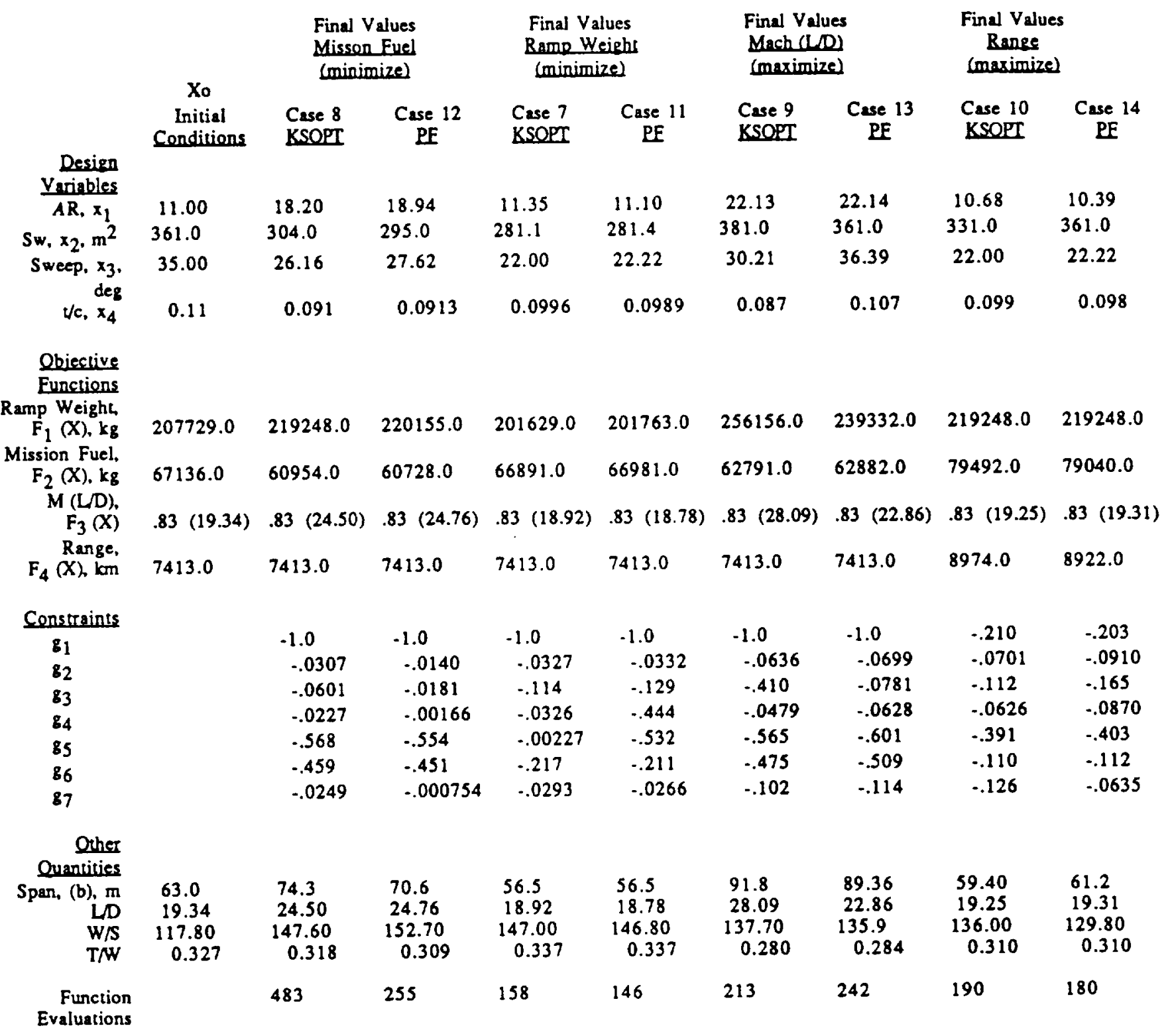


Design Variables

$A \mathrm{R}, \mathrm{x}_{1}$

$\mathrm{Sw}, \mathrm{x}_{2}, \mathrm{~m}^{2}$

Sweep, $x_{3}$, deg

$\mathrm{v}, \mathrm{x}_{4}$

Objective Functions

Ramp Weight,

$\mathrm{F}_{1}(\mathrm{X}), \mathrm{kg}$

Mission Fuel,

$\mathrm{F}_{2}(\mathrm{X}), \mathrm{kg}$

$M(L / D), F_{3}(X)$

Range, $F_{4}(X), k m$

Constraints

$\mathrm{g}_{1}$
$\mathrm{~g}_{2}$
$\mathrm{~g}_{3}$
$\mathrm{~g}_{4}$
$\mathrm{~g}_{5}$
$\mathrm{~g}_{6}$
$\mathrm{~g}_{7}$

Other Quantities

Span, (b), $m$

$\mathrm{L} / \mathrm{D}$

W/S

TN

Function Evaluations
Table 3

Two Objective Design Results

\begin{tabular}{ccc} 
& Ramp Weight and Mission Fuel (minimize) & \\
\cline { 2 - 3 } Case 1 & Case 3 & Case 5 \\
KSOPT & PE & Global Criteria \\
& & \\
14.51 & 10.28 & 12.31 \\
289.0 & 369.0 & 282.0 \\
24.50 & 22.17 & 22.00 \\
0.0948 & 0.0946 & 0.0958
\end{tabular}

206268.0

62353.0

$.83(21.77)$

7413.0

$$
\begin{aligned}
& -1.0 \\
& -.0352 \\
& -.116 \\
& -.0334 \\
& -.537 \\
& -.385 \\
& -.0341
\end{aligned}
$$

64.7

21.77

146.20

0.329

325

$$
\begin{gathered}
205499.0 \\
65803.0 \\
.83(19.84) \\
7413.0
\end{gathered}
$$

$-1.0$

$-.148$

$-.349$

$-.161$

$-.529$

$-.263$

$-.254$

58.9

19.84

114.0

0.331

121
202360.0

64647.0

.83 (19.97)

7413.0

$-1.0$

$-.0334$

$-.120$

$-.0334$

$-.481$

$-.281$

$-.0243$

\section{5}

19.97

146.80

0.336

98 
Table 4

Three Objective Design Results

\begin{tabular}{rccc} 
& \multicolumn{3}{c}{ Ramo Weight and Mission Fuel (minimize) } \\
& Case 2 & and $M(\mathrm{D})$ (maximize) & Case 6 \\
& KSOPT & Case 4 & GlobalCriteria \\
Design Variables & & & \\
\hline$A R, \mathrm{x}_{1}$ & 16.87 & 15.49 & 11.64 \\
Sw, $\mathrm{x}_{2}, \mathrm{~m}^{2}$ & 365.0 & 291.0 & 286.0 \\
Sweep, $\mathrm{x}_{3}, \mathrm{deg}$ & 26.39 & 22.12 & 24.20 \\
$\mathrm{~V}, \mathrm{x}_{4}$ & 0.083 & 0.089 & 0.099
\end{tabular}

Objective Functions

Ramp Weight,

$\mathrm{F}_{1}(\mathrm{X}), \mathrm{kg}$

Mission Fuel,

$\mathrm{F}_{2}(\mathrm{X}), \mathrm{kg}$

$M(L / D), F_{3}(X)$

Range, $F_{4}(X), k m$

228716.0

210065.0

202162.0

62041.0

61564.0

65980.0

$.83(22.81)$

$.83(19.29)$

7413.0

7413.0

Constraints

$\begin{array}{ll}\mathbf{g}_{1} & -1.0 \\ \mathbf{g}_{2} & -.0956 \\ \mathbf{g}_{3} & -.171 \\ \mathbf{g}_{4} & -.0961 \\ \mathbf{g}_{5} & -.599 \\ \mathrm{~g}_{6} & -.465 \\ \mathrm{~g}_{7} & -.118\end{array}$

$-1.0$

$-1.0$

$-.0305$

$-.0405$

$-.0921$

$-.0267$

$-.543$

$-.402$

$-.0839$

$-.134$

$-.0416$

$-.466$

$-.249$

$-.0485$

Other Quantities

Span, (b), $m$ L/D

T/W

78.4
25.09
128.50
0.297

63.4

22.08

147.60

0.323

54.4

19.29

144.60

0.336

Function Evaluations

62

174

73 
Table 5

Best Single Objective Results

\section{Case}

12

7

9
Objective

Fuel

Weight

LD
Method

PF

KSOPT

KSOPT
Final Value

$60728.0 \mathrm{~kg}$

$201629.0 \mathrm{~kg}$

28.09 


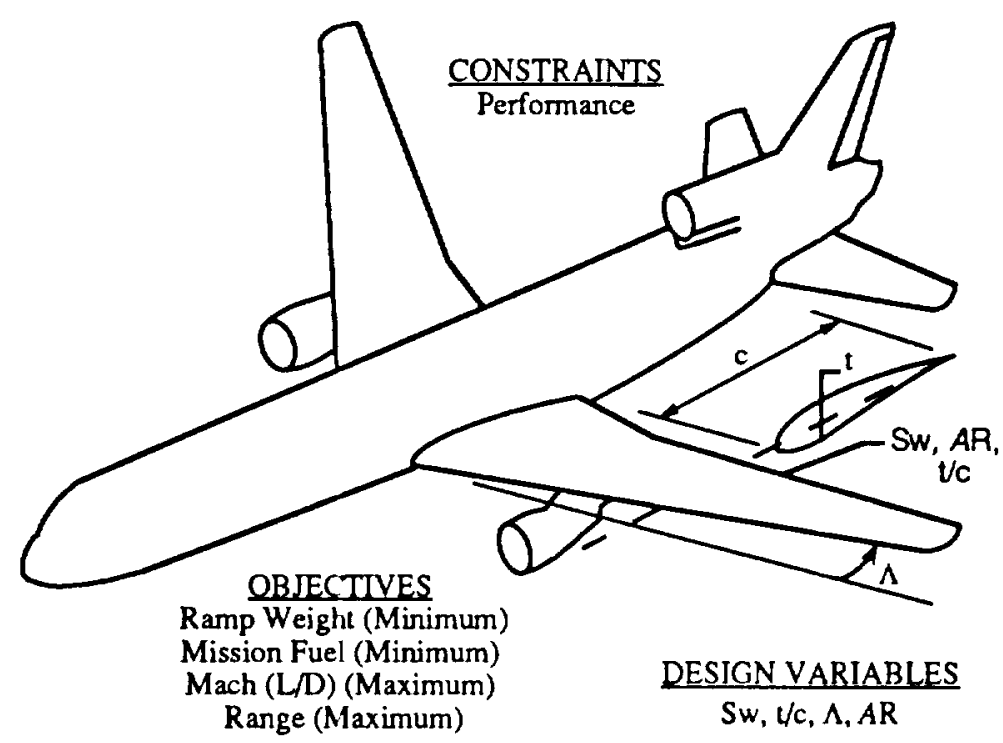

Figure 1. Objectives, Design Variables and Constraints

PRIMARY MISSION PROFILE

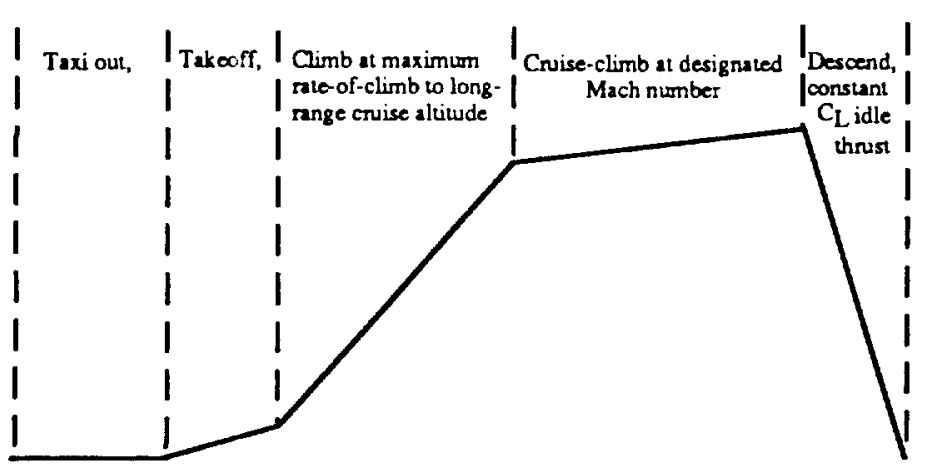

RESER VE PROFILE DOMESTIC OPERATIONS

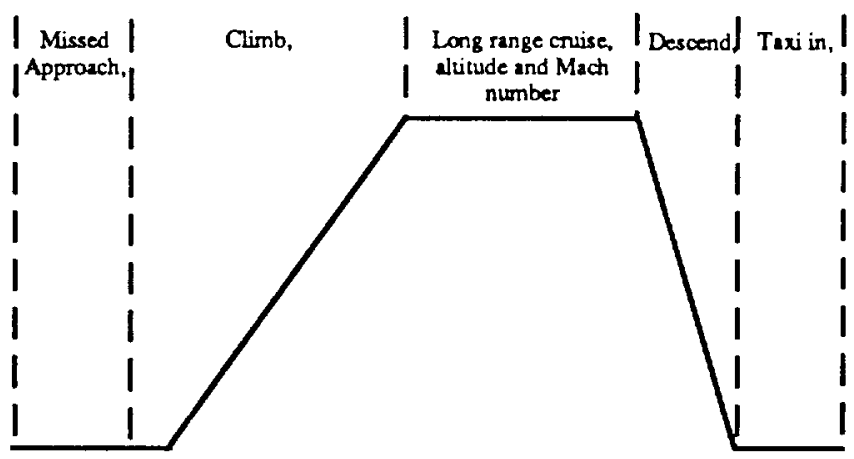

Figure 2. Mission Profile 


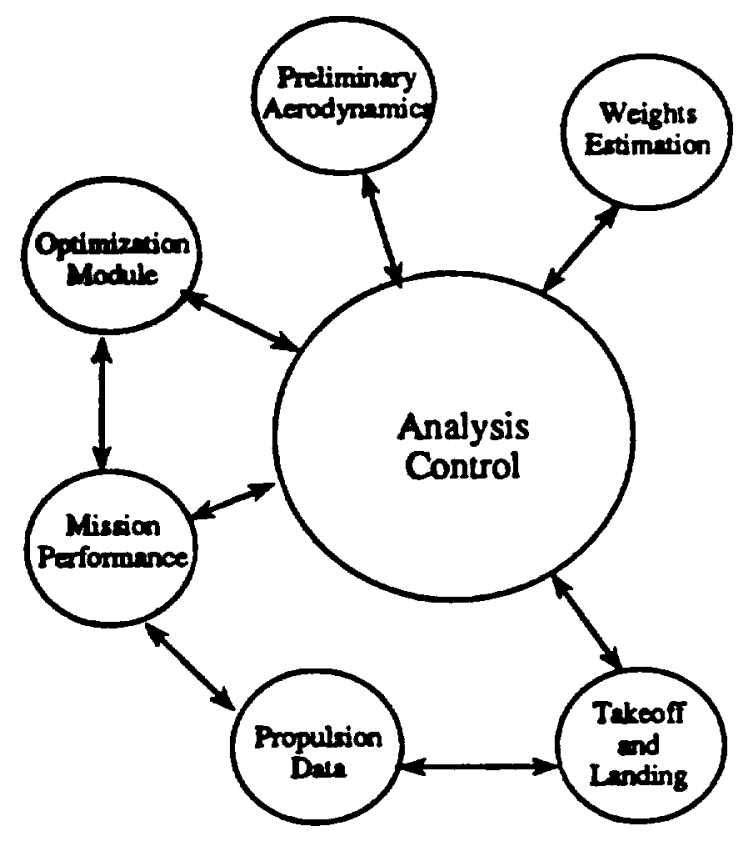

Figure 3. FLOPS Primary Modules

SINGLE OBJECTIVE OPTIMIZATION CHANGE FROM INITIAL CONDITIONS

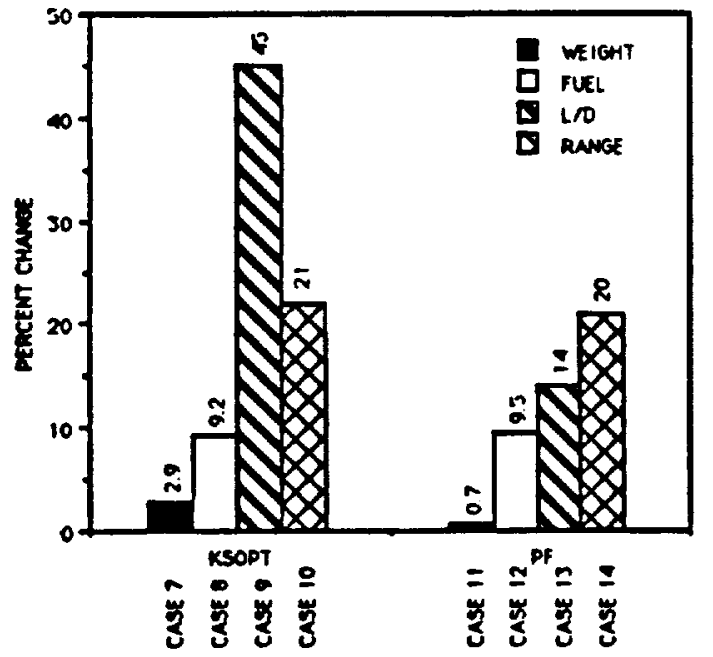

Figure 4
RAMPWEIGHT AS A FUNCTION OF ASPECT RATIO AND THICKNESS RATIO

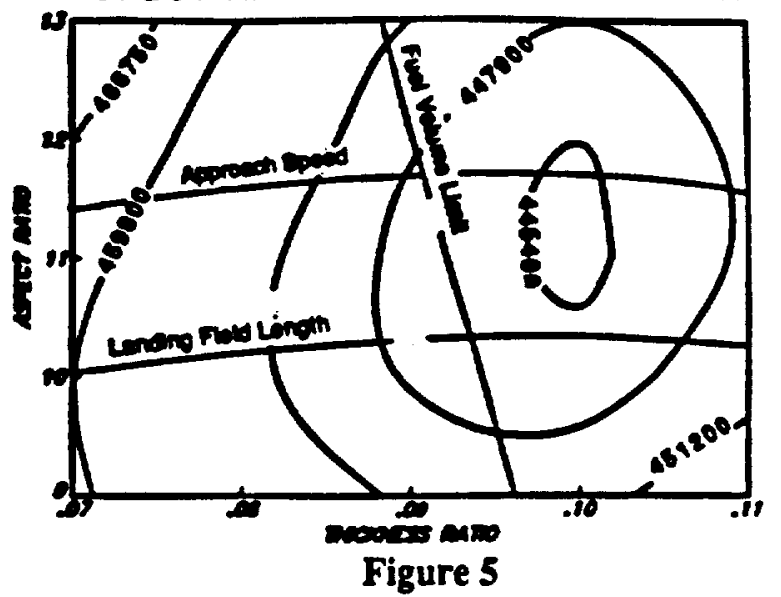

MISSION FUEL AS A FUNCTION OF ASPECT RATIO AND THICKNESS RATIO

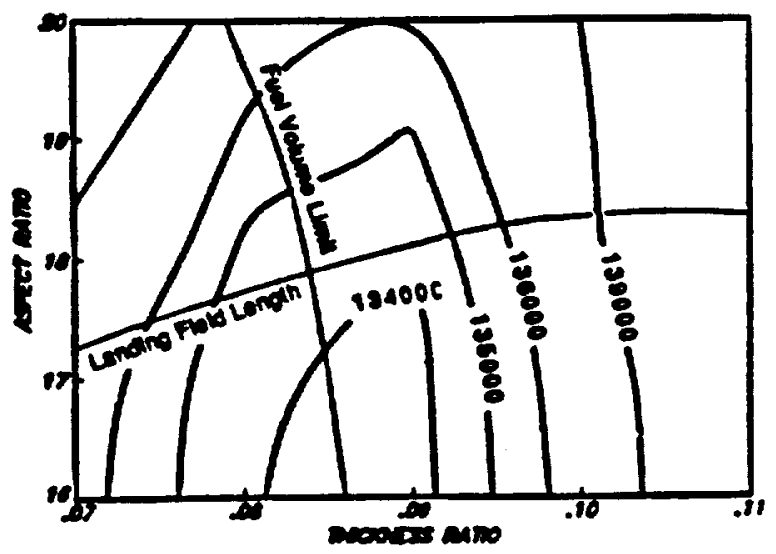

Figure 6

MACH (L/D) AS A FUNCTION OF ASPECT RATIO AND THICKNESS RATIO

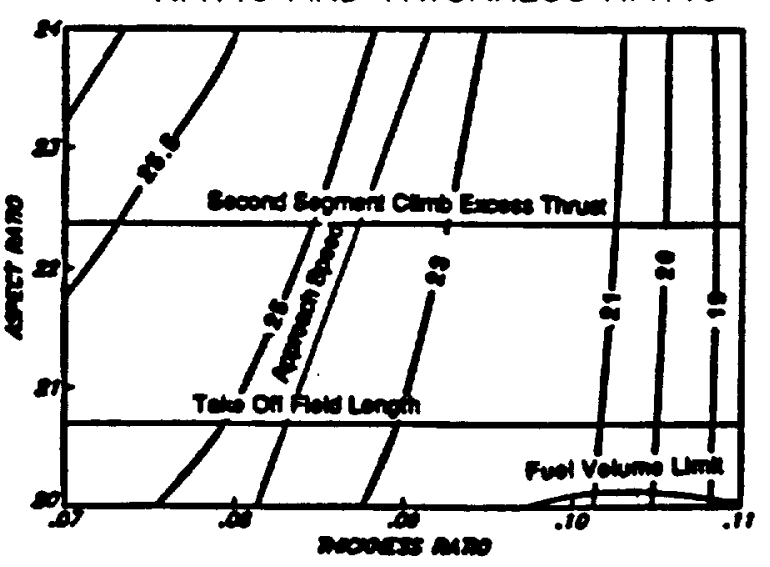

Figure 7 
TWO OBJECTIVE OPTIMIZATION

COMPROMISE FROM SINGLE OBJECTIVE CASES

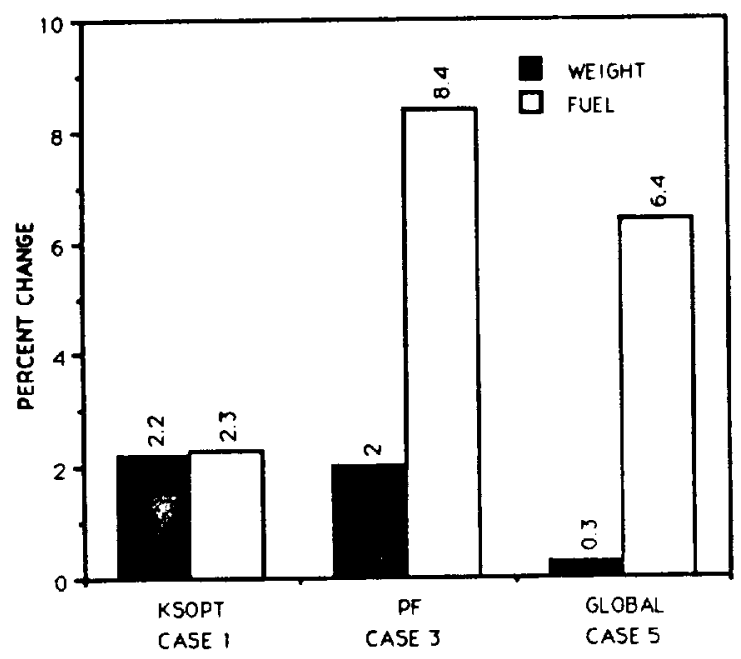

Figure 8
TWO OBJECTIVE OPTIMIZATION COMPROMISE

FROM BEST SINGLE OBJECTIVE CASES

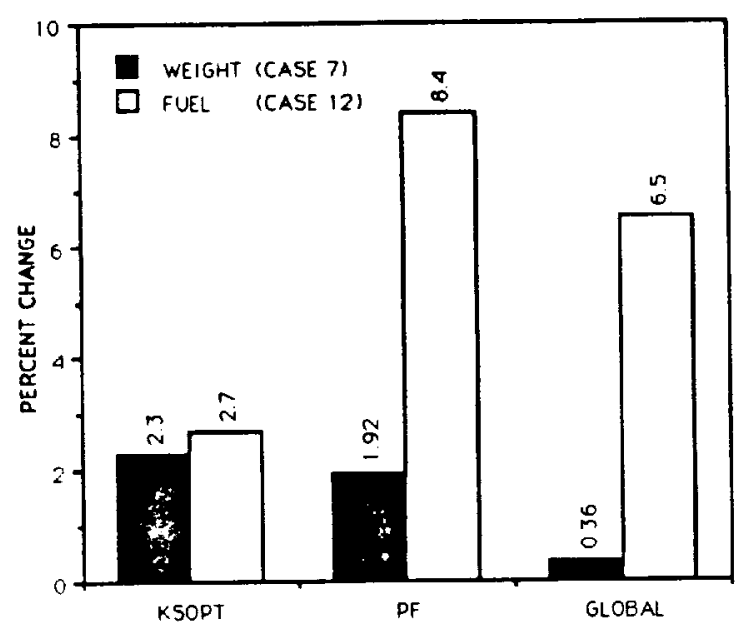

Figure 10
THREE OBUECTIVE OPTIMIZATION COMPROMISE FROM SINGLE OBJECTIVE CASES

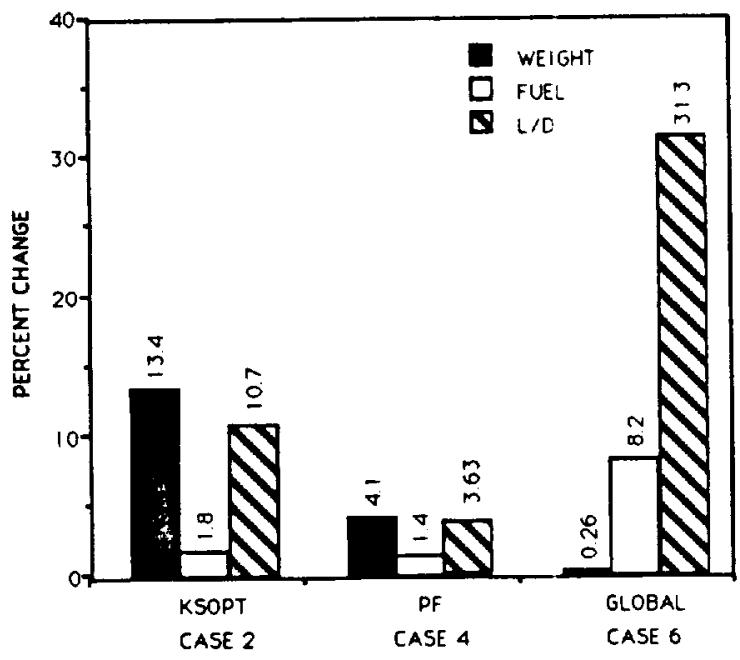

Figure 9
THREE OBUECTIVE OPTIMIZATION COMPROMISE FROM BEST SINGLE OBJECTIVE CASES

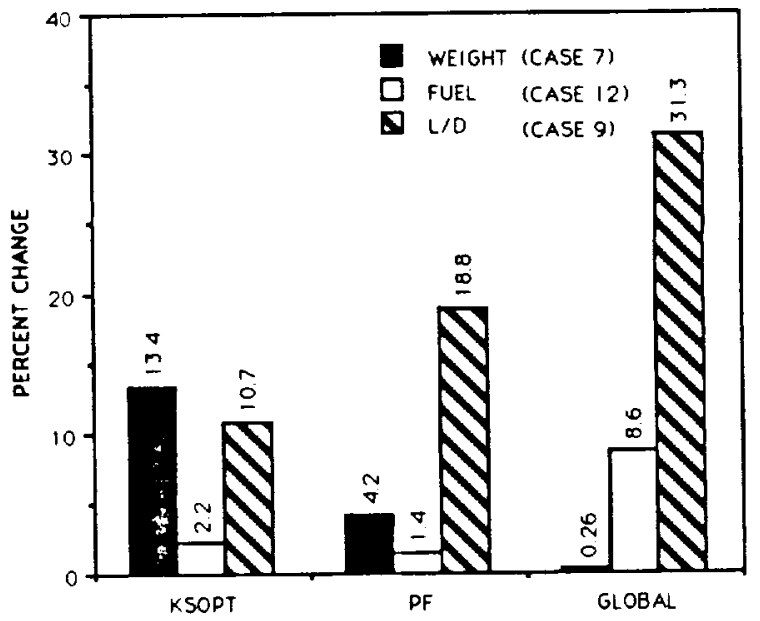

Figure 11 



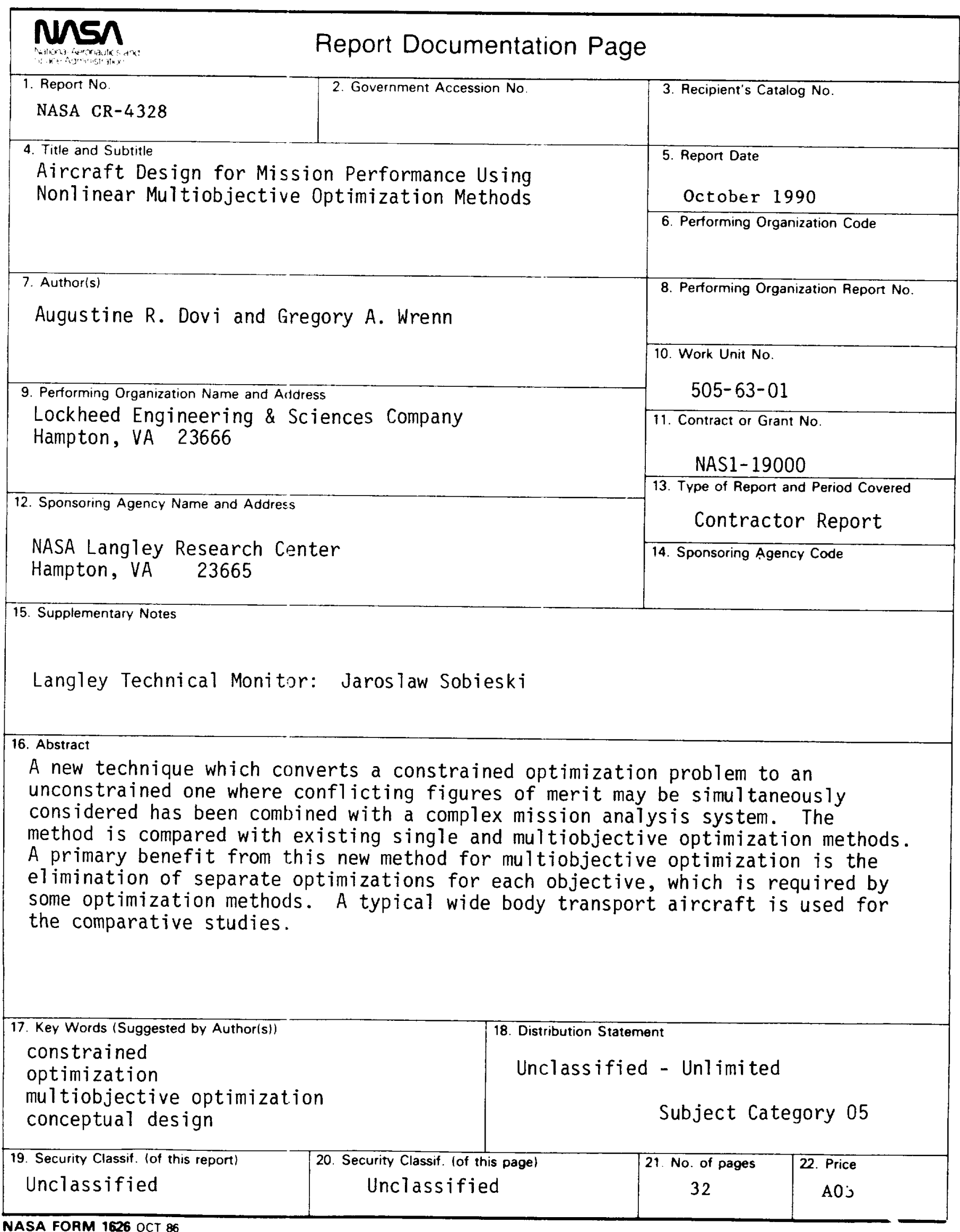

NASA FOAM 1626 OCT 86 
